part of King Leopold's case. It is, from beginning to end, a covert attack on M. Civiale, and an open glorification of Sir Henry Thompson.

Dr. Koepl commences by assuming that Civiale's publication was influenced "more by personal motives than by scientific considerations," and by asserting that the case contains "some inaccuracies," which he feels called upon to correct.

We have thus before us motives, merits, and facts. With the first the profession has no concern. I do not pretend to penetrate as deeply into the human heart as Dr. Koepl; but I can say that I have had repeated conversations with M. Civiale on the King's case. I never heard him utter a single word in disparagement of Sir Henry Thompson; but he evidently felt hurt by the manner in which the case had been handled by the English journals, and especially by The Lancet. The comments of The Lancet are again referred to in the posthumous publication. Mr. Walter Coulson, however, has omitted them in his translation; judiciously, I think, because they were extraneous matter, referring to the question of merit.

The "merits" of respective operators cannot, I submit, be fairly determined in the present state of the case. If they are to be discussed, M. Civiale's friends will not be found wanting; but the elements of an impartial discussion do not yet exist, because the evidence is incomplete. For my own part, I am not disposed to detract from the merit which really belongs to Sir Henry Thompson in this case. It is sufficiently great without rendering it necessary for his friends to strip everyone else and exhibit him in the position of one who, having come in at the end of a long and tedious case, claims all the glory of the cure because he was the last attendant on the patient.

"M. Civiale crushed a stone for the King without obtaining a cure; Sir Henry Thompson cured the King by crushing the calculus he found"-ergo, \&c. So reasons Dr. Koepl. But, if I were inclined to be discourteous, I might remark that a proposition put in this way has no significance for a scientific man. We want, however, neither praise nor condemnation of individuals. What the profession desires to see is a complete account of King Leopold's case, from beginning to end. Disease and death knock at all doors alike. Let us, therefore, abstract the rank of the patient, and of the eminent men by whom he was attended, and let us have a plain, complete history of the case, as if, to borrow the expression of M. Civiale, "the King had been a simple mortal like ourselves."

M. Civiale has given the beginning of the case; Professor Langenbeck can furnish the middle, and Sir Henry Thompson the end. When the whole case shall have been placed before the profession, they will be able to form a competent opinion, but not until then.

In the meantime, and to clear the ground, I may examine in what "the inaccuracies" of M. Civiale consist, and on what facts Dr. Koepl founds his correction of these alleged inaccuracies. Let us follow them seriatim.

1. Dr. Koepl insists " that nothing has justified the opinion of M. Civiale when he affirmed that the King's bladder contained several calculi and a small tumour seated near the neck of the bladder." With submission to the Doctor, the opinion was justified by the only evidence of which the nature of the case admitted-i.e., by the positive result of an examination made by the first lithotritist in Europe. M. Civiale affirmed that the bladder contained more than one calculus, simply because he felt more than one calculus in that organ. In like manner, his delicate and practised touch enabled him to detect the presence of a small tumour near the neck of the bladder. To this positive evidence, Dr. Koepl opposes the negative evidence of Professor Langenbeck and Sir H. Thompson. But how, in the name of common sense, could either of these surgeons have detected several calculi in the bladder when their predecessor had been powdering these same calculi for months, or, at all events, had left behind him only a minute fragment of them.

2. The second alleged "inaccuracy" in M.'Civiale's statement refers to the condition of the King's health at the time when MI. Civiale was called in. Dr. Koepl says that "it was then very satisfactory." MI. Civiale, from his own observation, and from the reports made to him, concluded that the King's general health was very unsatisfactory. Between these contradictory statements 1 do not presume to judge; but it is right to remark that in a note* appended to this portion of the case, M. Civiale mentions that the statements which he received respecting the King's general health were contradictory. It may, besides, be admitted that the same state of health which seemed "satisfactory" to Dr. Koepl might have appeared less favourable to a lithotomist who was about to perform a difficult and-under the circumstances of the case-a hazardous operation.

3. The final examination of the King's bladder was made on the 17th of July, 1862. That examination-the seventh which had been made-led MI. Civiale to declare " that the bladder contained nothing more,-neither calculus nor fragments." How does Dr. Koepl meet this conclusion? By an insinuation. Civiale had misgivings in his mind. But what was the surgeon-in-ordinary about? It would be far more important to know what he felt than what $M$ Civiale thought. Did he endeavour to clear up his doubts, or confirm his suspicions? Did he, in a word, examine the King's bladder? He was in the habit of washing out that organ daily. Did he find the calculous matter or fragment left behind by Civiale? and if so, when? Upon these important points Dr. Koepl is silent, apparently thinking it quite enough to insinuate that the calculus successfully removed by Sir Henry Thompson was one formed on a fragment left behind by M. Civiale. There is here a striking error of reasoning. The stone removed by Sir Henry was confessedly left in the bladder by Professor Langenbeck; and it remains to be proved whether or no the German operator received the nucleus from the French surgeon. The only fact bearing upon this point is one mentioned quite incidentally by Dr. Koepl at the conclusion of his letterviz., "that his Majesty had, after the departure of Civiale a fragment embedded in the superior parietes of the urethra canal." This is an important fact in the history of the case. On the 27 th June, 1862 , M. Civiale had extracted a fragment from the neck of the bladder, and this he considered to be the last one, inasmuch as he could not detect any other fragment during his subsequent examinations. He left Brussels on the 17th July, and never saw the King, professionally, afterwards, having been virtually dismissed from attendance on his Majesty on the 2nd August, 1862.

It would be interesting to know whether the detection of this fragment in the urethra was communicated to $M$. Civiale, and at what time. Was the fragment composed of uric acid, or was it phosphatic?

These and many other points remain to be cleared up. So far ats I can see, the only "inaccuracy" really committed by M. Civiale, in the case which you have published, consisted in his incautious adoption of a report relative to the manner in which the formation of the calculus extracted by Sir Henry Thompson was explained to the King.

Paris, Jan. 11, 1870. I am, Sir, your obedient servant,

H. GREeN.

\section{RETURNS OF SICKNESS TO THE POOR-LAW BOARD.}

To the Editor of THE LANCET.

Sin,-An article in the Poor-lew Chronicle of January 7th will, I think, astonish many Poor-law medical officers, as it states that the permanent paupers should have been included in the recent return of sickness furnished to the Poor-law Board. Very few did this, counting those only actually on the books for the appointed day, and thus a fallacious estimate of the sickness has been made. If too late to remedy this error, it might at least be in a measure corrected by a return of the permanent paupers in each reliering officer's district.

I am, Sir, your obedient servant,

Jan. 18th, 1870.

HENRY J. MaThews, Medical Office, Horsham Lnion.

Health of Garibaldi. - Garilaldi, according to the Globe, is at present suffering severely from his old enemy, rheumatism. Cnable to hold a pen in his hand, he has had to give up all correspondence; and he sees only the members of his own family.

* This note does not appear in the transation formarded by Mr. Walter 